\title{
EFFECTS OF PAVEMENT SURFACE TEMPERATURE ON THE MODIFICATION OF URBAN THERMAL ENVIRONMENT
}

\author{
SARAT, Adebayo-Aminu and EUSUF, Muhammad Abu \\ International Islamic University Malaysia \\ Email: adesarat@yahoo.com
}

\begin{abstract}
Urban centres continue to experience escalating average summer temperature over the last fifty years. Temperature in the urban core cites have been rising due to rapid growth of urbanization in the latter half of the twentieth century (Akbari et al., 1989). Outdoor experiments were conducted to investigate the effects of different movement of materials on the urban thermal environment. Meteorological conditions such as air temperature, pavement surface temperature, Relative humidity and wind velocity were recorded to determine temperature differences among Asphalt/concrete, interlocking bricks and grass surfaces.
\end{abstract}

Keywords: Porous, non-porous pavement, temperature difference, urban thermal environment.

\section{INTRODUCTION}

Urbanization results in a landscape with significantly modified surface characteristics. The lower values of reflectivity to solar radiation, surface moisture availability, and vegetative cover, along with the higher values of anthropogenic heat release and surface roughness combine to result in higher air temperatures in urban areas relative to their rural counterparts. During sunny summer days, cities can experience peak temperatures that average $20^{\circ} \mathrm{C}$ to $30^{\circ} \mathrm{C}$ higher than surrounding rural areas, causing an 'urban heat island' effect (Rosenfeld et al., 1998). This phenomenon is attributed to a combination of factors. Excess heat from surfaces that are heated by solar radiation is transferred to the surrounding air through convective heat transfer (Kim, 1992). Anthropogenic sources of heat, such as heat exhausted from power generation and transportation systems; average city albedo contributes to urban heat island effects (Taha, 1997) Heating of pavements by sunlight has been suggested as one of the causes of "urban heat islands," the excess heating of cities compared to their surroundings. The reasoning is that pavements of most cities are made of asphalt concrete (AC) which is quite dark. This means that it absorbs most of the visible light that falls on it. (Asphalt pavements similarly absorb the invisible infrared solar radiation.) Thus the energy in the absorbed sunlight becomes heat in the pavement (Pomerantz et al., 2000). This is because AC pavement is one of the darkest surfaces found in the cities; as a result, the air is heated by the pavement making the cities hotter than surrounding rural areas. Dark pavement materials can store heat than natural surfaces and lighter-coloured materials
(Davies et al., 1992; Asaeda et al., 1996; Taha et al., 1997).

Asaeda and Vu (1993) revealed that around noon, surface temperature of Asphalt concrete pavement can reach more than $55^{\circ} \mathrm{C}$, and the surfaces releases more than $350 \mathrm{~W} / \mathrm{m} 2$ and $600 \mathrm{~W} / \mathrm{m} 2$ to the atmosphere in the form of sensible heat and longwave radiation, respectively. The sensible heat directly heats the air, while the upward longwave radiation can increase the thermal load on the pedestrian and cause great thermal discomfort. Similarly, less intense, the heated concrete pavement can also cause great thermal discomfort to pedestrian.

The use of light-coloured surfaces enhance the reflection of incoming solar radiation to reduce solar heating during daytime and hence decrease the need for cooling, planting trees to reduce solar temperature through shading and evaporative cooling (Akbari et al., 1992).

Plants play a vital role in urban ecosystem function by providing canopy effect (Oke, 1978) water vapour to the environment through the process of evapotranspiration, reduction of air pollutant and carbon emission. It also improves the urban aesthetics (US Forest service, 1991).

The purpose of this study is to determine temperature differences between Asphalt concrete AC, interlocking bricks and grass surfaces and to show the benefits of the use of grass surfaces in the study area.

\section{MATERIAL AND METHODS}

This study was conducted in Kulliyyah of Architecture \& environmental Design (KAED) of International Islamic University (IIUM) $308 \mathrm{~N}, 101^{\circ} 42 \mathrm{~N}$ 
Gombak Campuslocated in Kuala Lumpur, which is the largest city in Malaysia in terms of population size.

Malaysia climate can be described as typical tropical climate. According to Malaysian meteorological station, Characteristics climate of Malaysia are uniformtemperature, the annual variation is less than $3^{\circ} \mathrm{C}$, Daily temperature ranges between $8^{\circ} \mathrm{C}$ to $12^{\circ} \mathrm{C}$, the average temperature at night usually between $21^{\circ} \mathrm{C}$ to $24^{\circ} \mathrm{C}$.

Average monthly relative humidity is between $10 \%$ to $90 \%$, vary with location and month high humidity and plenty of rain. In the case of temperature, the diurnal variation of relative humidity is greater than the annual changes. Average daily minimum can be as low as $42 \%$ during dry months and as high as $70 \%$ during months slow. The mean daily maximum did not vary much from place to place higher than $94 \%$. It may be as high as $100 \%$.

Winds are generally light. Malaysia is situated in the equatorial doldrums very rare to have a cloudless sky at all even in severe drought. Malaysia is also rare to have a few days with no direct sunlight except during the northeast monsoon. Wind: although the wind in Malaysia is generally light and variable, there are changes in wind flow patterns. Based on these changes, the four seasons can be distinguished, namely the southwest monsoon, northeast monsoon and Monsoon two seasons shorter.

Sunshine and Solar Radiation: as a maritime country close to the equator, Malaysia naturally has abundant sunshine and then the sun. However, it is rare to have a full day with completely clear sky even in periods of drought. Cloud cover can reduce the sun and then sun. On average, the country received about 6 hours of sunlight a day.

Evaporation: among all the factors affecting the rate of evaporation, cloudiness and temperature are the two most important factors are interrelated. Cloudy day will mean sunshine and thus less sunlight causes the temperature to low. Tests showed that evaporation data shows the months of cloudy or rainy with low evaporation rates, while the driest months are the months with high evaporation rates

A field experiment was conducted to obtain meteorological data such as ambient atmospheric temperature; relative humidity and wind velocity were monitored in a standard screen height of 2.0 above the sample surface.

The selected pavement surfaces were the representative of typical urban and sub-urban thermal environment. The information gathered over the observational period was screened so as to exclude rainy, overcast and high mean wind speed days and

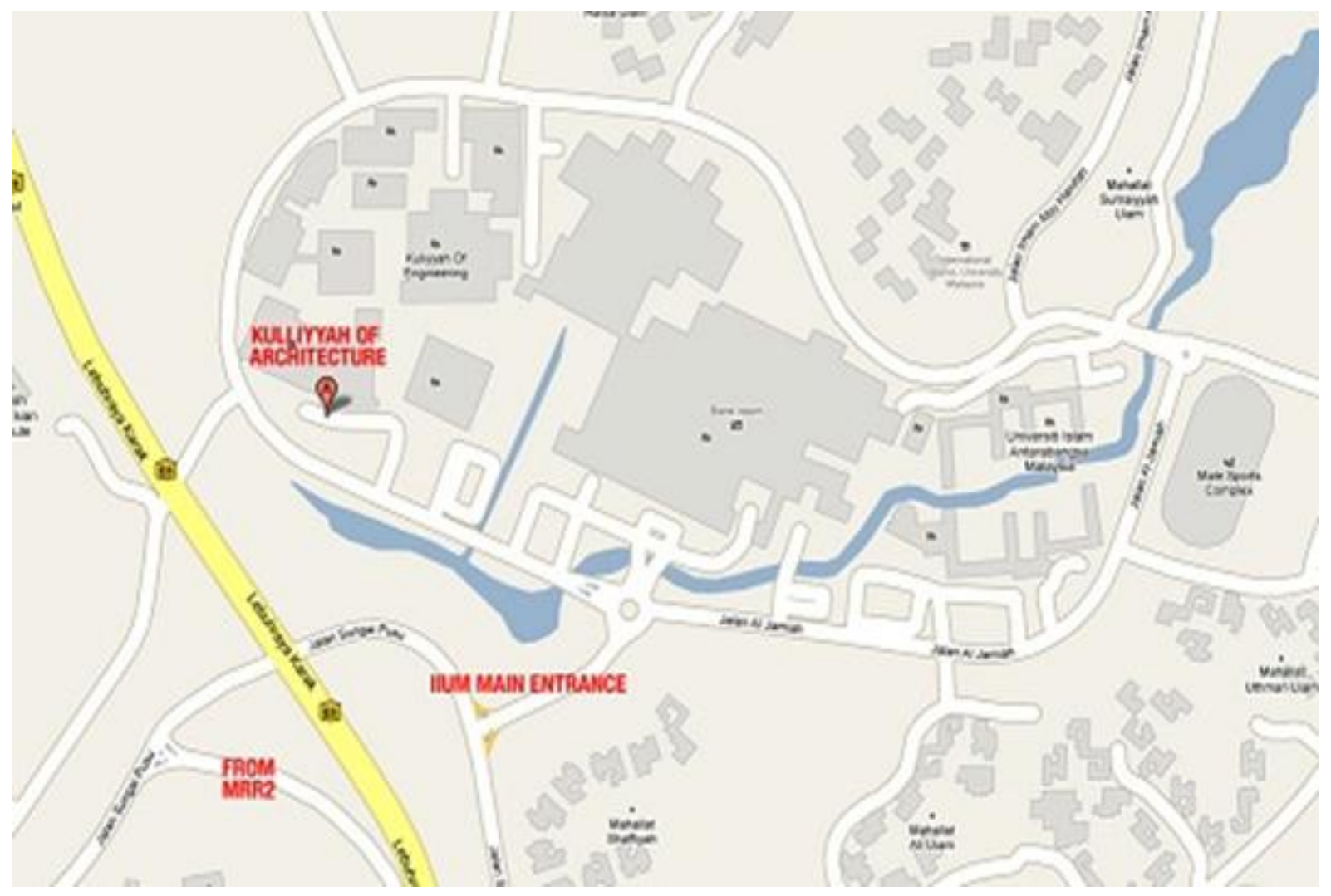

Figure 1. Location map of IIUM showing KAED 
eventually one set of data corresponding to $4^{\text {th }}$ April 2011 was chosen as representative fair weather conditions of tropic, where weather somewhat more inland was sunny and warm.

Because the aim of this research is to determine, if present, the pure effects of the pavement surfaces on temperature values, calm, windless or less than $2 \mathrm{~m} / \mathrm{s}$ daily, clear, cloudiness days were sought due to the temperature reducing effects of cloudiness and wind. Although, observations have been carried out for nearly a year but only the temperature values on $16^{\text {th }}$ of February 2011 was chosen as a representative fair weather conditions of tropic, where weather somewhat more inland was sunny and warm.

The ambient temperature (denoted as Ta for the purpose of this research) and relative humidity were measured using TESTO 625 with an accuracy of $+0.02^{\circ} \mathrm{C}$, Scope and Laser Sighting Infrared Thermometer to measure surface temperature. During the observation, the and wind speed was measured using anemometer with the accuracy of $0.01 \mathrm{~m} / \mathrm{s}$

\section{RESULTS AND DISCUSSION}

From the temperature values obtained on a standard screen height of 2.0 above the sample surface on 10 dry, calm and cloudless days, the following results were found.

\section{Differences in Temperature on Pavement Surfaces}

From the Table 1, an evident difference between the surface temperatures can be seen. While Asphalt/ concrete (AC) is the hottest surface, its temperature begins to rise at noon with average temperature of $34^{\circ} \mathrm{C}$, up to $46^{\circ} \mathrm{C}$ at $4.30 \mathrm{pm}$. Air temperature begin to increase, Asaeda et al. (1996) showed that the pavement surface temperature peaks from one to two hours after the solar noon and gradually falls which is in conformity with present study. The high surface temperature of asphalt/concrete which is regarded as porous pavement can be explained by the effect of the pore size in pavement materials on the surface moisture transfer ( $\mathrm{Vu}$ Thanh et al, 1997). At the same time, temperature at the surface of interlocking bricks reached only $35^{\circ} \mathrm{C}$ while the surface temperature of the natural grass was only $20^{\circ} \mathrm{C}$, this low value shows the importance of plant in cooling in the urban areas.

The meteorological data recorded in every 10 minutes interval. To illustrate this, hourly observation data are presented in Figure 3 and Table 2.

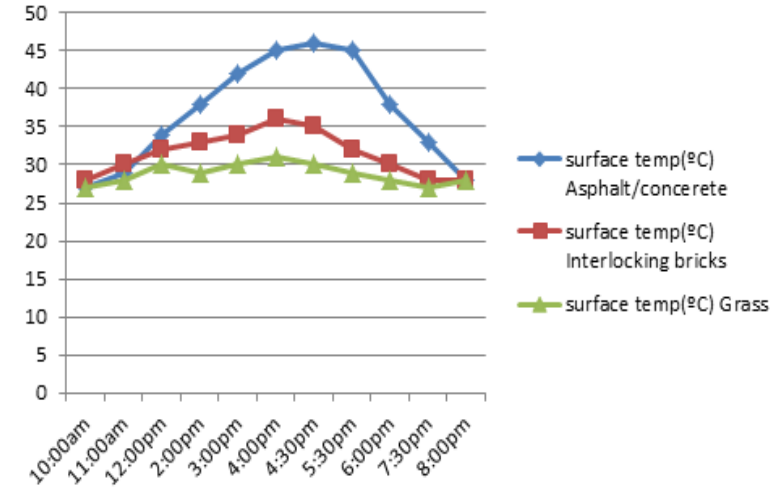

Figure 2. Surface Temperature on Asphalt, Brick and Grass

Table1. Hourly Surface Temperatures on Asphalt, Brick and Grass

\begin{tabular}{cccc}
\hline Time & $\begin{array}{c}\text { Surface } \\
\text { Temp. }\left({ }^{\mathbf{O}} \mathbf{C}\right) \\
\text { Asphalt/ } \\
\text { Concrete }\end{array}$ & $\begin{array}{c}\text { Surface Temp. } \\
\left({ }^{\mathbf{0}} \mathbf{C}\right) \\
\text { Interlocking } \\
\text { Bricks }\end{array}$ & $\begin{array}{c}\text { Surface } \\
\text { Temp. }\left({ }^{\mathbf{0}} \mathbf{C}\right) \\
\text { Grass }\end{array}$ \\
\hline 10:00am & 27 & 28 & 27 \\
11:00am & 29 & 30 & 28 \\
12:00pm & 34 & 32 & 30 \\
2:00pm & 38 & 33 & 29 \\
3:00pm & 42 & 34 & 29 \\
4:00pm & 45 & 35 & 30 \\
4:30pm & 46 & 34 & 30 \\
5:30pm & 45 & 32 & 29 \\
6:00pm & 38 & 30 & 28 \\
7:30pm & 33 & 28 & 27 \\
\hline
\end{tabular}

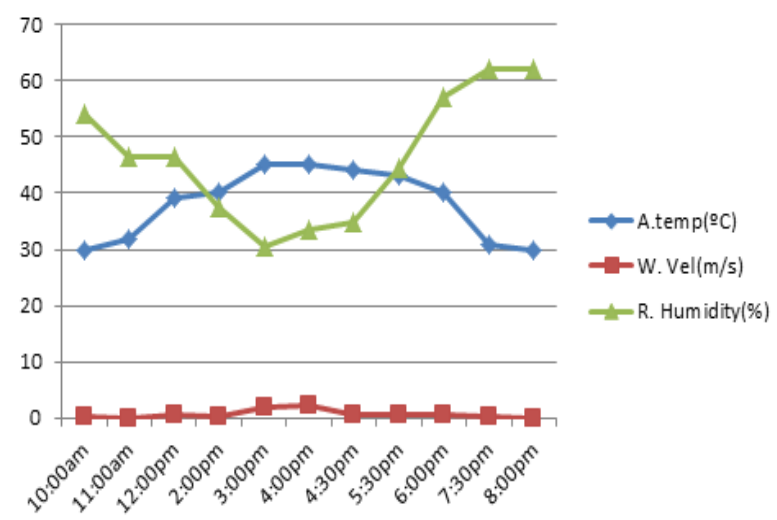

Figure 3. Hourly Average Temperature, Wind Velocity, and Humidity

Maximum ambient temperature reached approximately $45^{\circ} \mathrm{C}$, while the wind speeds and the percentage of relative humidity were found minimum. These conditions are believed to be representative of tropical days in this area. 
Table 2. Hourly Average Temperature, Wind Velocity, and Humidity

\begin{tabular}{cccc}
\hline Time & $\begin{array}{c}\text { Air Temperature } \\
\left({ }^{\mathbf{0}} \mathbf{C}\right)\end{array}$ & $\begin{array}{c}\text { Wind } \\
\text { Velocity } \\
(\mathbf{m} / \mathbf{s})\end{array}$ & $\begin{array}{c}\text { Relative } \\
\text { Humidity } \\
(\mathbf{\%})\end{array}$ \\
\hline 10:00am & 30 & 0.31 & 54 \\
11:00am & 32 & 0 & 46.5 \\
12:00pm & 39 & 0.74 & 46.5 \\
2:00pm & 40 & 0.33 & 37.5 \\
3:00pm & 45 & 2 & 30.5 \\
4:00pm & 45 & 2.28 & 33.5 \\
4:30pm & 44 & 0.71 & 35 \\
5:30pm & 43 & 0.44 & 44.5 \\
6:00pm & 40 & 0.58 & 57 \\
7:30pm & 31 & 0.2 & 62 \\
8:00pm & 30 & 0 & 62 \\
\hline
\end{tabular}

\section{CONCLUDING REMARKS}

In urban area, plants play a functional role on the climate by moderating the extreme climatic values such as high temperatures seen above artificial surfaces like asphalt concrete which are mostly found in cities.

The utilization of the normal porous pavement material does not improve the thermal environment of the urban areas since the surface of this kind of pavement is usually very dry and evaporation cannot occur. Because of evaporation from porous surface and evapotranspiration from grass surface, the temperature of the porous pavement surface is lower than non-porous surface. The nonporous surface materials can absorb a large amount of incoming solar radiation which increases its surface temperature and cause the variation of urban thermal environment.

From the results of field experiment, it is remarkable that significant improvement of the urban micro-scale thermal environment can be achieved if more grass is planted, reduces the use of $\mathrm{AC}$ by ceramic. A study on urban micro climate is incomeplete without studying on Albedo; our further objecttive is to investigate on urban albedo.

\section{REFERENCE}

Akbari H., Garbesi E. \& Martien. P. (1989). Controlling summer heat islands. Lawrence Berkeley Laboratory, Energy Analysis Program, Berkeley, CA trees and white surfaces. Proceedings of the 1992 ACEEE summer study on energy efficiency in buildings, America Council for an Energy Efficient Economy, Washington D.C

Akbari H., Taha, H. and Sailor, D. (1992). Measured savings in air conditioning from shade.

Asaeda T., Vu, T.C. \& Wake, A. (1996). Heat Storage of pavements and its effect on the lower temperature. Atmospheric Environment, 30(3), 413-27.

Davis S.D., Huang \&, J. Winnett, S. (1992). Cooling our communities: A guidebook on tree planting and light-coloured surfacing (LBL-31587) (56). United States Environmental Protection Agency and Lawrence Berkeley Laboratory.

Oke, T.R. (1978). Boundary layer climates, William Clowes and Sons Limited, London.

Pometantz M., Pon, B. Akbarians, H. \& Chang, S. (2000). The effect of pavements' temperatures on air temperature in large cities (LBNL-3442). Lawrence Berkeley Laboratory, Energy Analysis Program, Berkeley, CA. p. 373.

Rosenfeld, A.H., Akbari, H. Romm, J.R. \& Pomerantz, M. (1998). "Cool Communities: Strategies for Heat Island Mitigation and Smog Reduction," Energy and Buildings, 28, 51-62.

Taha, H. (1997). "Modeling the Impacts of LargeScale Albedo Changes on Ozone Air Quality in the South Coast Air Basin," Atmospheric Environment, 31, 1667-1676.

US Forest Service (1991). Urban and community forest; A guide for the Northeast and Midwest United States. Benefits and values factsheet. USDA Forest Service, Washington, D. C. p.20.

Vu T.C., Asaeda, T. \& Armfield, S. (1997). Study of the heating and evaporation processes in the urban canopy based on a LES model. Proceedings of sixth Australian Heat and Mass Transfer conference. 